\title{
Antifungal activity of extracts from Piper aduncum leaves prepared by different solvents and extraction techniques against dermatophytes Trichophyton rubrum and Trichophyton interdigitale
}

\author{
Maximillan Leite Santos ${ }^{1 \S}$, Chaiana Froés Magalhães ${ }^{1 \S}$, Marcelo Barcellos da Rosa ${ }^{2}$, \\ Daniel de Assis Santos ${ }^{3}$, Beatriz Gonçalves Brasileiro ${ }^{4}$, Leandro Machado de Carvalho ${ }^{2}$, \\ Marcelo Barreto da Silva ${ }^{5}$, Carlos Leomar Zani ${ }^{6}$, Ezequias Pessoa de Siqueira ${ }^{6}$, \\ Rodrigo Loreto Peres ${ }^{8}$, Anderson Assunção Andrade ${ }^{1,7}$ \\ ${ }^{1}$ Faculdade de Ciências da Saúde, Universidade Vale do Rio Doce, Governador Valadares, MG, Brazil. \\ ${ }^{2}$ Departamento de Química, Universidade Federal de Santa Maria, Santa Maria, RS, Brazil. \\ ${ }^{3}$ Departamento de Microbiologia, Instituto de Ciências Biológicas, Universidade Federal de Minas \\ Gerais, Belo Horizonte, MG, Brazil. \\ ${ }^{4}$ Departamento de Fitotecnia, Universidade Federal de Viçosa, Viçosa, MG, Brazil. \\ ${ }^{5}$ Departamento de Ciências Agrárias e Biológicas, Universidade Federal do Espírito Santo, São Mateus, \\ ES, Brazil. \\ ${ }^{6}$ Laboratório de Química de Produtos Naturais, Centro de Pesquisas René Rachou, Fiocruz, Belo \\ Horizonte, MG, Brazil. \\ ${ }^{7}$ Departamento de Microbiologia, Imunologia e Parasitologia, Universidade Federal do Triângulo \\ Mineiro, Uberaba, MG, Brazil. \\ ${ }^{8}$ Instituto Federal Baiano, Teixeira de Freitas, BA, Brazil
}

Submitted: October 07, 2011; Approved: April 04, 2013.

\begin{abstract}
The effects of different solvents and extraction techniques upon the phytochemical profile and anti-Trichophyton activity of extracts from Piper aduncum leaves were evaluated. Extract done by maceration method with ethanol has higher content of sesquiterpenes and antifungal activity. This extract may be useful as an alternative treatment for dermatophytosis.
\end{abstract}

Key words: antifungal activity, Piper aduncum L., dermatophytes, Trichophyton, extraction techniques.

Dermatophytes are a group of closely related fungi that affect keratinous tissue (skin, hair, and nails) of humans and other vertebrates, causing superficial infections, dermatophytosis, commonly known as ringworm or tinea. They belong to three anamorphic (asexual or imperfect) genera, Epidermophyton, Microsporum and Trichophyton (Weitzman and Summerbell, 1995). In recent years the number of infections caused by these fungi has increased considerably and Trichophyton rubrum has been the most common dermatophyte since the fifties of last century, ac- counting for $80-90 \%$ of the strains, followed by $T$. interdigitale (Seebacher et al., 2008).

The drugs used against dermatophytosis exhibit several side effects, have limited efficacy, and are very expensive (Gupta and Cooper, 2008; Kyle and Dahl, 2004). Such considerations have led to the search for alternative treatment methods, which have included plant extracts or plant-derived compounds based on the knowledge that plants have their own defense against fungal pathogens (Gurgel et al., 2005).

Send correspondence to A.A. Andrade. Laboratório de Microbiologia, Departamento de Microbiologia, Imunologia e Parasitologia, Instituto de Ciências Biológicas e Naturais, Universidade Federal do Triângulo Mineiro, Uberaba, MG, Brazil. E-mail: anderson@icbn.uftm.edu.br.

${ }^{\S}$ These authors contributed equally to this work. 
Piper aduncum L. (Piperaceae) is a tropical shrub widespread in South and Central America, growing naturally in the Amazon and in the Atlantic Forests of Brazil. Its extracts have displayed a broad range of antifungal activity and phytochemical studies have described the isolation of metabolites with antifungal effects (Baldoqui et al., 1999; Lago et al., 2004; Lentz et al., 1998; Okunade et al., 1997). Given these properties and the fact that currently no studies have adequately assessed the anti-Trichophyton activity of the $P$. aduncum, we aimed to study this plant for its effect against $T$. rubrum and T. interdigitale. Additionally, in view of the fact that solvent and extraction technique are fundamental parameters influencing secondary metabolites extraction, the effects of different solvents (ethanol and $\mathrm{n}$-hexane) and extraction techniques (maceration, ultrasonic, decoction and soxhlet) were determined on the phytochemical profile and anti-Trichophyton activity of extracts from $P$. aduncum leaves.

Leaves of $P$. aduncum (adult plants) were collected in the region of Governador Valadares city, state of Minas Gerais, Brazil. The plant was identified by one of us (B.G.B.) and a voucher specimen was deposited at the Faculdade de Ciências Biológicas e da Saúde, Universidade Vale do Rio Doce, under the number 423.

The powder of the air-dried leaves (15 g) was extracted with either $80 \%$ ethanol or n-hexane $(150 \mathrm{~mL})$ by different extraction techniques: (i) maceration for a week at room temperature; (ii) Soxhlet apparatus for $4 \mathrm{~h}$ at boiling temperature; (iii) decoction for $6 \mathrm{~h}$ at boiling temperature and (iv) ultrasonic extraction into the ultrasonic bath ( $40 \mathrm{kHz}$, QUIMIS) for $4 \mathrm{~h}$ at $20^{\circ} \mathrm{C}$. After filtration, the resulting solution was concentrated to dryness under reduced pressure using a rotary evaporator at a temperature lower than $40{ }^{\circ} \mathrm{C}$.

The Trichophyton strains employed in this study were either acquired from the American Type Culture Collection (ATCC, Rockville, MD) or were clinical isolates from the Laboratório de Micologia, Instituto de Ciências Biológicas, Universidade Federal de Minas Gerais. The reference strains were T. rubrum (ATCC 28189) and T. interdigitale (ATCC 9533).

The antifungal activity was determined by broth microdilution assay following the guidelines of the Clinical and Laboratory Standards Institute (CLSI) for filamentous fungi M38-A (CLSI, 2002), with modifications, as described previously (Santos and Hamdan, 2005). Test concentrations for extracts ranged from 0.005 to $5 \mathrm{mg} / \mathrm{mL}$. Fluconazole (Pfizer) was used as a standard antifungal agent at concentration ranging from 0.125 to $64 \mu \mathrm{g} / \mathrm{mL}$. The minimum inhibitory concentration (MIC) was defined as the lowest concentration of extract that completely inhibited visible growth of microorganisms in the microdilution wells and the minimum fungicidal concentration (MFC) was determined by sub-culturing the negative wells on potato dextrose agar (PDA) plate and was the lowest concentration that yielded negative sub-cultures.

Extracts were analyzed by Gas Chromatography/Mass Spectrometry (GC-MS) using Solid Phase Micro Extraction (SPME) analysis mode, as described previously (Siqueira et al., 2007).

The susceptibility profiles of $T$. rubrum (ATCC 28189) and T. interdigitale (ATCC 9533) for each evaluated extract showed nearly identical results (data not shown). Considering only the MIC values, both ethanol and hexane extracts obtained by different extraction methods showed the same result $(0.31 \mathrm{mg} / \mathrm{mL})$, except ethanol extract yielded by ultrasonic technique that displayed MIC of $0.62 \mathrm{mg} / \mathrm{mL}$. MFC values were either the same or twice higher than those of the corresponding MIC, ranging from $0.31 \mathrm{mg} / \mathrm{mL}$ to $1.25 \mathrm{mg} / \mathrm{mL}$. The maximum MFC was obtained with the ethanol extract yielded by ultrasonic extraction. Because the strongest lethal activity to the two reference species was achieved to ethanol extract obtained to maceration $(0.31 \mathrm{mg} / \mathrm{mL})$, we also assessed its activity against eight clinical isolates of Trichophyton strains. As shown in Table 1, the MICs of the fluconazole-resistant strains were identical to those of sensitive strains $(0.31 \mathrm{mg} / \mathrm{mL})$, and the MFC values ranged from $0.31 \mathrm{mg} / \mathrm{mL}$ to $0.62 \mathrm{mg} / \mathrm{mL}$.

The antifungal activity of members from Piperaceae species is well known. This plant family is among the most tested and has the highest number of positive results for the antifungal activity in a screening program of Latin American medicinal plants (Fenner et al., 2006). Specifically about $P$. aduncum, several pharmacological effects have been attributed to it, including antifungal activity. However, its anti-dermatophyte activity has not been adequately evaluated yet. At the best of our knowledge, it is the first time that quantitative MIC and MFC values were deter-

Table 1 - Antifungal activity of fluconazole and maceration-ethanol extract from Piper aduncum leaves against clinical isolates of Trichophyton strains.

\begin{tabular}{|c|c|c|c|}
\hline \multirow[t]{2}{*}{ Clinical strains } & \multirow{2}{*}{$\begin{array}{c}\text { Fluconazole } \\
\mathrm{MIC} \\
(\mu \mathrm{g} / \mathrm{mL})^{\mathrm{a}}\end{array}$} & \multicolumn{2}{|c|}{ Extract } \\
\hline & & $\begin{array}{c}\text { MIC } \\
(\mathrm{mg} / \mathrm{mL})^{\mathrm{a}}\end{array}$ & $\begin{array}{c}\mathrm{MFC} \\
(\mathrm{mg} / \mathrm{mL})^{\mathrm{a}}\end{array}$ \\
\hline T. rubrum (I) ${ }^{\mathrm{b}}$ & $>64.0$ & 0.31 & 0.62 \\
\hline T. rubrum (II) & 32.0 & 0.31 & 0.62 \\
\hline T. rubrum (III) ${ }^{\mathrm{b}}$ & $>64.0$ & 0.31 & 0.31 \\
\hline T. interdigitale $(\mathrm{I})^{\mathrm{b}}$ & $>64.0$ & 0.31 & 0.31 \\
\hline T. interdigitale $(\mathrm{II})^{\mathrm{b}}$ & $>64.0$ & 0.31 & 0.31 \\
\hline T. interdigitale (III) ${ }^{\mathrm{b}}$ & $>64.0$ & 0.31 & 0.31 \\
\hline T. interdigitale (IV) & 32.0 & 0.31 & 0.62 \\
\hline T. interdigitale $(\mathrm{V})$ & 16.0 & 0.31 & 0.31 \\
\hline
\end{tabular}

${ }^{a}$ Results are representative of at least two independent experiments, each performed in triplicate.

${ }^{\mathrm{b}}$ Fluconazole-resistant strains (MICs $\geq 64 \mu \mathrm{g} / \mathrm{mL}$ ). 
mined to extracts from $P$. aduncum leaves against Trichophiton species. Lentz et al. (1998) showed that of the 92 extracts from Honduran medicinal plants subjected to antifungal screens, ethanol extract (prepared by percolation) of $P$. aduncum displayed the broadest range of antifungal activity, including against $T$. interdigitale. However, as in this study the agar well tests were employed, neither MIC nor MFC values were determined.

In the present investigation all extracts evaluated showed a marked fungicidal effect. In many situations, fungicidal drugs are often preferred over drugs with fungistatic activity, since fungi recur more often when fungistatic, rather than fungicidal, drugs have been used. Therefore, considering that the relapse of infection remains a problem, particularly with tinea pedis/unguium, fungicidal activity is desirable for treatment of dermatophytic fungal infections (Kyle and Dahl, 2004).

The chemical composition of extracts was analyzed by GC-MS technique. The major constituents, compounds whose concentration was higher than $3 \%$ in at least one of the extracts, and their relative concentrations are given in Table 2. Extracts are predominantly composed of sesquiterpenes (cariofilene, $\alpha$-calacorene, $\gamma$-elemene, Cis- $\gamma$-cadinene, germacrene $\mathrm{D}$, linalool oxide, nerolidol, $\beta$-elemene, $\delta$-cadinene, $\alpha$-cariofilene). Monoterpene (linalool) and fatty alcohol (falcarinol) were also characterized as main components.

Navickiene et al. (2006) analyzed the essential oil obtained by hydrodistillation of $P$. aduncum leaves, occurring in Brazil, by GC-MS and found that it was active against Cladosporium cladosporioides and C. sphaerospermum.
The analysis revealed a high amount of monoterpenes (45.2\%), among which linalool occurred as the most abundant $(31.7 \%)$, but the sesquiterpenes were predominant $(52 \%)$. Our data confirm the predominance of sesquiterpenes and monoterpenes among the volatile compounds of $P$. aduncum leaves, but the chromatographic profiles were not the same in both studies. This discrepancy could be due to many factors, including different soil type and climate conditions, time of collection of plant materials and extraction techniques. One obvious reason for this discrepancy is that the samples were different (essential oil from fresh leaves $v s$. ethanol or hexane extracts from air-dried leaves). Another aspect that has to be taken into account is that previous researches have shown that phytochemical composition of $P$. aduncum can differ widely when it grows at different geographical location. Vila et al. (2005) reported high sesquiterpene contents in Panama samples, whilst Bolivian samples were composed predominantly of monoterpenes. Additionally, the phenylpropanoid dillapiol has been detected as major constituent in the Amazonian species (Maia et al., 1998) but not in specimens occurring in southern region of Brazil (Navickiene et al., 2006), as used in this study, or in samples from Panama and Bolivia (Vila et al., 2005).

Regarding different procedures for the preparation of crude extracts, ultrasonic technique with ethanol was less efficient than both maceration and decoction in extracting the major volatile compounds (Table 2). The reduced content of terpenes observed in the extract prepared by ultrasonic technique can be related, at least in part, to its lower anti-Trichophyton activity, since these compounds are known for their antifungal activities (Paduch et al., 2007).

Table 2 - Major compounds identified in the extracts from Piper aduncum leaves prepared by different solvents and extraction methods.

\begin{tabular}{|c|c|c|c|c|c|}
\hline \multirow[t]{3}{*}{ Compounds } & \multicolumn{5}{|c|}{ Concentration (\%) } \\
\hline & \multicolumn{3}{|c|}{ Ethanol } & \multicolumn{2}{|c|}{ Hexane } \\
\hline & Maceration & Ultrasonic & Decoction & Maceration & Decoction \\
\hline Caryophyllene & 6.78 & 7.56 & 5.63 & 6.06 & 5.51 \\
\hline$\alpha$-calacorene & - & 5.41 & - & - & - \\
\hline$\gamma$-elemene & 14.48 & - & 13.49 & 13.27 & 14.78 \\
\hline Cis- $\gamma$-cadinene & 17.16 & - & 15.39 & - & - \\
\hline Falcarinol & - & 6.06 & - & - & - \\
\hline Germacrene D & 17.16 & - & 15.39 & 17.84 & 18.93 \\
\hline Linalool & 2.44 & 8.0 & 1.89 & 0.74 & 0.56 \\
\hline Linalool oxide & 0.55 & 4.34 & - & - & - \\
\hline Nerolidol & 13.41 & 18.45 & 15.24 & 15.26 & 15.78 \\
\hline$\beta$-elemene & 3.12 & - & 2.68 & 3.57 & 3.83 \\
\hline$\delta$-cadinene & 6.01 & - & 5.73 & 3.51 & 4.51 \\
\hline$\alpha$-caryophyllene & 7.49 & 8.25 & 6.06 & 6.65 & 6.26 \\
\hline Total & 88.6 & 58.07 & 81.5 & 66.9 & 70.16 \\
\hline
\end{tabular}

- Not detected. 
Among the identified compounds, germacrene $\mathrm{D}$ and $\delta$ cadinene, which were previously reported to have antifungal activity (Cheng et al., 2005; Sahin et al., 2004), were absent in ultrasonic-ethanol extract, but occurred in appreciable amounts in all other extracts. Indeed, a plant extract is a complex chemical mixture, whose biological activity relies upon synergistic effects between their constituents (Cos et al., 2006). Thus, it is difficult to attribute its activity to a single or particular constituent. Additionally, phytochemical studies of $P$. aduncum have reported the isolation of other metabolites with antifungal activity such as chromenes, dihydrochalcones and prenylated benzoic acids (Baldoqui et al., 1999; Lago et al., 2004).

In conclusion, our findings demonstrated that extracts from $P$. aduncum leaves have strong fungicidal activity against Trichophyton species, including those exhibiting resistance to fluconazole. This good antifungal performance suggests that $P$. aduncum extracts may be useful as an alternative treatment for dermatophytosis caused by Trichophyton species. In addition, the maceration method using ethanol is a suitable way to prepare these bioactive extracts. Our data reinforce the importance of choosing the correct extraction scheme to ensure that active constituents are maintained during the extract preparation process.

\section{Acknowledgments}

The authors are grateful to the Fundação de Amparo à Pesquisa do Estado de Minas Gerais (FAPEMIG) to financial support. Thanks are also due to the Coordenadoria de Aperfeiçoamento de Pessoal de Nível Superior (CAPES) for a postgraduate fellowship to CFM.

\section{References}

Baldoqui DC, Kato MJ, Cavalheiro AJ, Bolzani VS, Young MC, Furlan MA (1999) A chromene and prenylated benzoic acid from Piper aduncum. Phytochemistry 51:899-902.

Cheng SS, Lin HY, Chang ST (2005) Chemical Composition and Antifungal Activity of Essential Oils from Different Tissues of Japanese Cedar (Cryptomeria japonica). J Agric Food Chem 53:614-619.

Clinical and Laboratory Standards Institute (2002) Reference Method for Broth Dilution Antifungal Susceptibility Testing of Filamentous Fungi. CLSI document M38-A. Clinical and Laboratory Standards Institute, Wayne.

Cos P, Vlietinck AJ, Berghe DV, Maes L (2006) Anti-infective potential of natural products: how to develop a stronger in vitro 'proof-of-concept'. J Ethnopharmacol 106:290-302.

Fenner R, Betti AH, Mentz LA, Rates SM (2006) Plantas utilizadas na medicina popular brasileira com potencial atividade antifúngica. Braz J Pharm Sci 42:369-394.
Gupta AK, Cooper EA (2008) Update in Antifungal Therapy of Dermatophytosis. Mycopathologia 166:353-367.

Gurgel LA, Sidrim JJ, Martins DT, Cechinel Filho V, Rao VS (2005) In vitro antifungal activity of dragon's blood from Croton urucurana against dermatophytes. J Ethnopharmacol 97:409-412.

Kyle AA, Dahl MV (2004) Topical therapy for fungal infections. Am J Clin Dermatol 5:443-451.

Lago JH, Ramos CS, Casanova DC, Morandim AA, Bergamo DC, Cavalheiro AJ, Bolzani VS, Furlan M, Guimarães EF, Young MC, Kato MJ (2004) Benzoic Acid Derivatives from Piper Species and Their Fungitoxic Activity against Cladosporium cladosporioides and C. sphaerospermum. J Nat Prod 67:1783-1788.

Lentz DL, Clark AM, Hufford CD, Meurer-Grimes B, Passreiter CM, Cordero J, Ibrahimi O, Okunade AL (1998) Antimicrobial properties of Honduran medicinal plants. J Ethnopharmacol 63:253-263.

Maia JG, Zohhbi MD, Andrade EH, Santos AS, da Silva MH, Luz AI, Bastos CN (1998) Constituents of the essential oil of Piper aduncum L. growing wild in the Amazon region. Flav Frag J 13:269-272.

Navickiene HM, Morandim AA, Alécio AC, Regasini LO, Bergamo DC, Telascrea M, Cavalheiro AJ, Lopes MN, Bolzani VS, Furlan M, Marques MO, Young MC, Kato MJ (2006) Composition and antifungal activity of essential oils from Piper aduncum, Piper arboreum and Piper tuberculatum. Quim Nova 29:467-470.

Okunade AL, Hufford CD, Clark AM, Lentz D (1997) Antimicrobial Properties of the Constituents of Piper aduncum. Phytother Res 11:142-144.

Paduch R, Kandefer-Szerszen M, Trytek M, Fiedurek J (2007) Terpenes: substances useful in human healthcare. Arch Immunol Ther Exp 55:315-327.

Sahin F, Güllüc M, Daferera D, Sökmen A, Sökmen M, Polissiou M, Agar G, Özer H (2004) Biological activities of the essential oils and methanol extract of Origanum vulgare ssp. vulgare in the eastern Anatolia region of Turkey. Food Control 15:549-557.

Santos DA, Hamdan JS (2005) Evaluation of broth microdilution antifungal susceptibility testing conditions for Trichophyton rubrum. J Clin Microbiol 43:1917-1920.

Seebacher C, Bouchara JP, Mignon B (2008) Updates on the Epidemiology of Dermatophyte Infections. Mycopathologia 166:335-352.

Siqueira EP, Alves TM, Zani CL (2007) Fingerprint of volatiles from plant extracts based on SPME-GC-MS. Rev Bras Farmacogn 17:565-571.

Vila R, Tomi F, Mundina M, Santana AI, Solis PN, Lopez Acre JB, Balderrama Iclina JL, Inglesias J, Gupta MP, Casanova J, Cañigueral S (2005) Unusual composition of the essential oils from the leaves of Piper aduncum. Flav Frag J 20:67-69.

Weitzman I, Summerbell RC (1995) The dermatophytes. Clin Microbiol Rev 8:240-259.

All the content of the journal, except where otherwise noted, is licensed under a Creative Commons License CC BY-NC. 